\title{
Chromosome Variation and HMW Glutenins in Synthetic Hexaploid Wheats (Triticum turgidum ssp. dicoccum/Aegilops tauschii)
}

\author{
N. Daskalova ${ }^{1}$, S. Doneva ${ }^{2}$ and P. Spetsov ${ }^{3 *}$ \\ 1Plant Production Department, Technical University, Varna 9010, Bulgaria \\ ${ }^{2}$ Dobroudja Agricultural Institute, 9520 General Toshevo, Bulgaria \\ ${ }^{3}$ College of Konstantin Preslavsky University of Shumen, Dobrich 9302, Bulgaria
}

(Received 4 December 2015; Accepted 4 February 2016;

Communicated by F. Békés)

\begin{abstract}
Seven synthetic hexaploid wheats (Triticum dicoccum/Aegilops tauschii) were subjected for investigation. Numerical variation of chromosome number in $F_{1}$ hybrids between three synthetics and common wheat varieties, was recorded. Hexaploid amphiploids (SHW) formed gametes with aneuploid chromosome number at a frequency of 13.2 and $14.8 \%$ as male and female parents, respectively. We speculated that the frequency of aneuploids in the generation might depend on variability of $\mathrm{BA}^{\mathrm{u}}$ - and $\mathrm{D}$-genomes of synthetic parents, and could be used for increasing the genetic diversity in common wheat. The HMW-glutenins analysis divided two lines in SHW530 and 532 due to different genes present in the B-genome, and increased them to 9 synthetic lines. The subunits $1 \mathrm{Dx} 1.5+1 \mathrm{Dy} 10$ was predominantly observed in the synthetics. Two other allelic variants 1Dx2+1Dy11 and $1 \mathrm{Dx} 4+1 \mathrm{Dy} 10.1$ were found in four lines and appeared as new genes in SHW originated from Aegilops tauschii. The synthetic hexaploid lines could play a significant role as novel germplasm resources for improving the grain quality of bread wheat.
\end{abstract}

Keywords: Aegilops tauschii, tetraploid wheat, mitotic chromosomes, glutenins, synthetic amphiploids

Abbreviations: SHW - synthetic hexaploid wheat; HMW-GS - high-molecular-weight glutenin subunits; IPGR - Institute for Plant and Genetic Resources - Sadovo, Bulgaria

\section{Introduction}

Common wheat (Triticum aestivum L., $2 \mathrm{n}=42$, AABBDD) is a globally important food crop and will become even more significant as the world's population increases. Domesticated hexaploid wheat has evolved from two spontaneous hybridization events. Tetraploid T. turgidum wheat $(2 \mathrm{n}=28$, AABB $)$ hybridized with diploid Aegilops tauschii Coss. $(2 \mathrm{n}=14$, DD) followed by spontaneous chromosome doubling is the commonly quoted concept for the origin of common wheat (Feldman 2001). However, it is widely recognized that only a limited number of individuals of parents were involved in the origin and 
evolution of hexaploid wheat. Thus, the genetic diversity of T. aestivum is fairly narrow compared with that of its two donor species, and most of the genetic variation found in tetraploid wheat and Aegilops tauschii is not available in the present wheat germplasm.

The genetic resources of tetraploid and diploid wheats, including Aegilops species, can be used as primary resources of elite genes for breeding of modern wheat cultivars. The production of synthetic amphiploids is an effective and rapid way of introgressing desirable traits from related species into domesticated wheats (Goncharov et al. 2007). Using the genetic resources of wild relatives is the best strategy to improve the quality and productivity of durum and common wheat. Numerous studies have been carried out to produce and investigate wheat-alien hybrids in order to clarify the inheritance and gene control of important traits in segregating populations. Synthetic hexaploid wheats (SHW) are good example as resulting products of wide hybridization in developing novel genetic lines and SHW-derived wheat varieties (Plamenov and Spetsov 2011; Li et al. 2014). Genes of interest can be introgressed into common wheat by the 'bridge' of resynthesized hexaploid or amphidiploids, obtained from crossing the tetraploid wheats with Ae. tauschii, in a manner analogous to the evolution of hexaploid wheat.

The study aimed to investigate the somatic chromosome number in $\mathrm{F}_{1}$ hybrids, obtained by crossing three synthetic wheats (Triticum turgidum ssp. dicoccum/Aegilops tauschii) with $T$. aestivum varieties, and identify HMW-glutenin subunits in seven synthetic amphiploids as potential genetic sources for wheat quality improvement.

\section{Materials and Methods}

The investigated seven SHW (Nos 32, 106, 107, 530, 531, 532 and 83/27) are presented in Table 1 [genome formulae followed the classification of Goncharov et al. (2009)]. Wheat variety Bezostaya-1 was used as a check in the protein analysis.

Five Aegilops tauschii accessions were successfully involved in breeding of synthetic wheats. Mitotic chromosome counting was performed in hybrid seedlings, obtained between single plants of Nos 530, 531 and 532 and some Bulgarian and Czech bread wheat varieties. A sample of 50 grains per line was crushed and ground to powder. Extraction of

Table 1. Pedigree of the synthetic hexaploid wheats employed in the study

\begin{tabular}{|c|l|}
\hline Breeding No. & \multicolumn{1}{|c|}{ Pedigree } \\
\hline 32 & $\mathrm{~F}_{1}\left(44961 /\right.$ Zagorka $\left.^{\mathrm{a}} / 45432\right) /$ Ae. tauschii No 19089 \\
106 & $\mathrm{~F}_{2}(44961 /$ Zagorka/45432)/Ae. tauschii No 22744 \\
107 & $45398 /$ Ae. tauschii No 22744 \\
530 & $510 \mathrm{~F}_{1}(45390 / 45398) /$ Ae. tauschii No 19088 \\
531 & $510 \mathrm{~F}_{1}(45390 / 45398) /$ Ae. tauschii No 30422 \\
532 & $510 \mathrm{~F}_{1}(45390 / 45398) /$ Ae. tauschii No 22744 \\
$83 / 27$ & T. dicoccum Khapli-III/Ae. tauschii No 001 \\
\hline
\end{tabular}

a'Bulgarian T. durum variety; T. dicoccum accessions 44961, 45390, 45398 and 45432 were obtained from the ICARDA, Syria; Aegilops tauschii accessions 001, 19088, 19089, 22744 and 30422 originated from the IPGR - Sadovo, Bulgaria. 
Table 2. Somatic chromosome number of $F_{1}$ hybrids, obtained by crossing three SHW (Nos 530, 531 and 532) to bread wheat cultivars

\begin{tabular}{|c|c|c|c|c|c|c|c|}
\hline \multirow{2}{*}{ Cross } & \multirow{2}{*}{ NPC } & \multicolumn{6}{|c|}{ Chromosome number } \\
\hline & & 41 & $41^{\mathrm{t}}$ & 42 & $42^{\mathrm{t}}$ & 43 & $\mathrm{O}$ \\
\hline Aglika/530-3 & 12 & 2 & 1 & 7 & 1 & & 1 \\
\hline Milena/530-1 & 1 & & & 1 & & & \\
\hline Pobeda/530-4 & 10 & & & 10 & & & \\
\hline Antitsa/530-3 & 6 & 1 & & 5 & & & \\
\hline Alana/530-1 & 5 & & & 4 & 1 & & \\
\hline Sulamit/530-2 & 1 & & & 1 & & & \\
\hline Vlasta/530-4 & 7 & & & 4 & & 3 & \\
\hline Slaveya/530-3 & 7 & & & 5 & 1 & 1 & \\
\hline Vlasta/530-2 & 9 & & & 8 & & 1 & \\
\hline Trakiya/530-4 & 12 & & & 12 & & & \\
\hline Svilena/530-4 & 7 & & & 7 & & & \\
\hline Enola/530-3 & 3 & & & 1 & & 2 & \\
\hline Polena/530-4-0 & 11 & & & 10 & & 1 & \\
\hline Slaveya/530-4 & 15 & & & 15 & & & \\
\hline Milena/532-2 & 1 & & & 1 & & & \\
\hline Slaveya/532-2 & 3 & & & 3 & & & \\
\hline Vlasta/532-6 & 11 & & & 11 & & & \\
\hline Total & 121 & $3(2.5)$ & 1 & $105(86.8)$ & 3 & $8(6.6)$ & 1 \\
\hline 530-3/Korona & 4 & & & 1 & & 3 & \\
\hline 530-5-6/Enola & 6 & & & 6 & & & \\
\hline 530-1-2/Karat & 7 & & & 7 & & & \\
\hline 530-4-0-1/Aglika & 9 & 2 & & 7 & & & \\
\hline 530-4-2-2/Aglika & 12 & & & 11 & & 1 & \\
\hline 531-2-2/Korona & 8 & 1 & & 7 & & & \\
\hline 532-1-1/Polena & 16 & & & 16 & & & \\
\hline 532-1-4/Aglika & 13 & & & 13 & & & \\
\hline 532-6-1-1/Meritto & 13 & 5 & & 7 & & & 1 \\
\hline Total & 88 & $8(9.1)$ & & $75(85.2)$ & & $4(4.6)$ & 1 \\
\hline
\end{tabular}

$\mathrm{NPC}$ - number of plants checked; $\mathrm{t}$ - telosome; $\mathrm{O}$ - others. Means (in \%) of hybrids with $2 \mathrm{n}=42$ are not statistically different. 
HMW-glutenins was performed on vertical apparatus followed the classical one-dimensional 12\% polyacrylamide gel, SDS-PAGE (Singh et al. 1991; Lafiandra et al. 1993). Universal system for arrangement and numbering of HMW-GS in wheat was employed and a method for Glu-1 score assessment as a criterion for wheat quality, too (Payne 1987).

The data were statistically evaluated by analysis of variance with $t$-test using Assistat version 7.7 beta (www.assistat.com). The genetic diversity at each locus was calculated using Nei's index (Nei 1973) and allelic frequencies were determined by summing the frequencies of alleles in the individual lines, dividing this total by the number of amphiploids.

\section{Results}

Chromosome number of hybrids obtained by crossing single plants of SHW530, 531 and 532 with some common wheat varieties, was counted (Table 2). A set of 121 hybrids, received from crosses with SHW as pollinators, were checked and $105(86.8 \%)$ proved to have 42 chromosomes. The rest hybrids exhibited different number of chromosomes: 8 (6.6\%) plants contained 43 chromosomes, $3(2.5 \%)-41$ chromosomes, and the remaining 5 individuals possessed different number of chromosomes with a telosome. From the reciprocal combination, $75(85.2 \%)$ plants of 88 investigated hybrids had 42 chromosomes. Four (4.6\%) plants possessed 43 chromosomes and eight (9.1\%) - 41 chromosomes. Some other karyotypes contained 40, 41 and $41^{\mathrm{t}}$ chromosomes. The difference between hybrids with $2 n=42$ in the reciprocal crosses was not statistically proven.

Eleven allelic variants of HMW-GS were detected in the synthetics (Table 3 and Fig. 1). The analysis differentiated two lines in Nos 530 and 532 due to different genes

Table 3. Allelic frequencies of HMW-GS at Glu-1 loci of nine SHW (including two lines in Nos530 and 532)

\begin{tabular}{|c|c|c|c|c|c|}
\hline Locus & Allele & Subunit & $\begin{array}{l}\text { Glu-1 quality } \\
\text { score }\end{array}$ & Number of lines & $\begin{array}{c}\text { Frequency } \\
\%\end{array}$ \\
\hline \multirow{3}{*}{$\begin{array}{c}G l u-A 1 \\
\mathrm{H}^{*}=0.49\end{array}$} & $\mathrm{a}$ & 1 & 3 & 2 & 22.2 \\
\hline & $\mathrm{x}$ & 1.1 & - & 6 & 66.6 \\
\hline & $\mathrm{c}$ & Null & 1 & 1 & 11.1 \\
\hline \multirow{5}{*}{$\begin{array}{c}G l u-B 1 \\
\mathrm{H}^{*}=0.72\end{array}$} & $\mathrm{~b}$ & $7+8$ & 3 & 4 & 44.4 \\
\hline & $\mathrm{f}$ & $13+16$ & 3 & 1 & 11.1 \\
\hline & $\mathrm{i}$ & $17+18$ & $3^{b}$ & 1 & 11.1 \\
\hline & $\mathrm{h}$ & $14+15$ & $3^{\mathrm{a}}, 2^{\mathrm{b}}$ & 2 & 22.2 \\
\hline & $\mathrm{k}$ & 22 & 1 & 1 & 11.1 \\
\hline \multirow{3}{*}{$\begin{array}{c}G l u-D^{t} 1 \\
\mathrm{H}^{*}=0.59\end{array}$} & $\mathrm{ah}$ & $1.5+10$ & - & 5 & 55.5 \\
\hline & - & $2+11$ & - & 2 & 22.2 \\
\hline & - & $4+10.1$ & - & 2 & 22.2 \\
\hline
\end{tabular}

aBranland and Dardevet 1985 .

bBahraei et al. 2004.

*Index for genetic diversity (Nei 1973). 


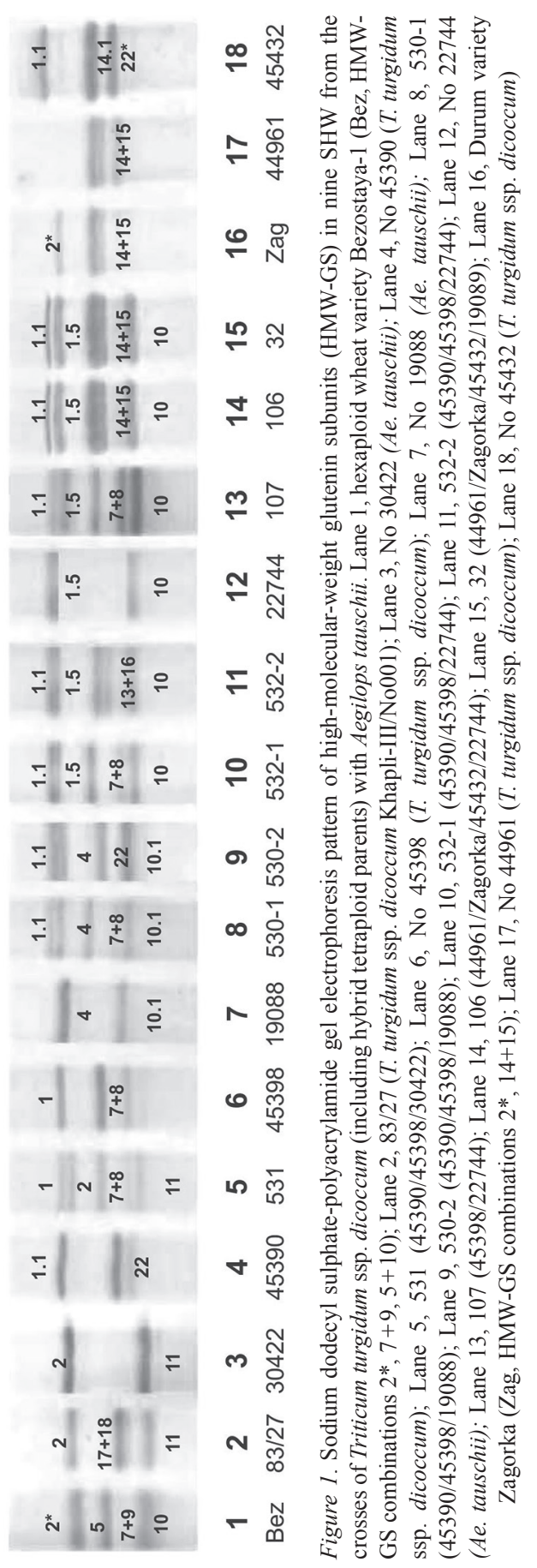


presented at the Glu-B1 locus, and increased them to 9 synthetic lines. Three of the variants were at the Glu-A1 locus, five-in Glu-B1 and three-in Glu-D 1 . At the Glu-A1 locus, the composition of alleles were only contributed by x-type subunits, viz. 1Ax1, 1Ax1.1 and Null, which are controlled by Glu-Ala, Glu-A1x and Glu-A1c. The $x$ allele was the most frequent (encoded for subunit 1.1) in six genotypes, followed by $a$ allele and $c$ allele. Five allelic variants were detected at the Glu-B1 locus. The most frequent was $b$ allele, controlled the pair $7+8$ in four genotypes, followed by $h$ allele, responsible for subunits $14+15$ in two synthetic lines.

From all HMW-GS variants, the D-genome alleles are essential for wheat dough and flour properties. The $G l u-D^{t} 1$ locus was contributed by three alleles with the combination of three x-type and y-type subunits (Table 3). The x-type subunits included 1.5, 2 and 4 variants, whereas the y-type subunits exerted the composition of 10,10.1 and 11. The most frequent subunit pair 1Dx1.5 + 1Dy10 encoded by allele Glu-Dlah, was observed in five synthetic amphiploids including SHW32 and 106, which have the same female hybrid parent (Table 1, Fig. 1).

\section{Discussion}

SHW and their synthetic derivative lines have been used as a means of introducing novel genetic variation into bread wheat (McIntyre et al. 2014; Rasheed et al. 2014). Beneficial SHW traits, such as large grains and high tiller number, were transferred into Sichuan varieties (Li et al. 2014; Ma et al. 2014). Mestiri et al. (2010) analyzed first generations of synthetic allohexaploids and found progenitor-dependent meiotic irregularities, such as incomplete homologous pairing, resulting in univalent formation and leading to aneuploidy in the subsequent generation. High variation of chromosome number in newly synthesized hexaploid wheats were also recorded by Niwa et al. (2010). We investigated somatic chromosome number in 209 hybrids between Nos 530, 531 and 532, and 15 bread wheat cultivars. It is known that bread wheat varieties usually form gametes with 21 chromosomes. Thus, some of the synthetic plants as male or female in crosses, produced gametes with different chromosome number, at a frequency of $13.2-14.8 \%$. We speculated that the frequency of aneuploids in the generation might depend on variability of $\mathrm{BA}^{\mathrm{u}}$ - and D-genomes of synthetic parents, and could be used for increasing the genetic diversity in hybrid populations.

No y-type subunits at the Glu-Al locus were found, although some authors reported their associations with good bread-making quality in wheat (Rasheed et al. 2012). Subunits $1.5+10$ was discovered in SHW by William et al. (1993) and proved to have significant influence on bread-making traits (Tang et al. 2008).

Giraldo et al. (2010) analyzed 165 Spanish wheat landraces and found four, nine and three subunits at the Glu-A1, Glu-B1 and Glu-D1 loci, respectively. Subunits $1.1,14+15$, $22,1.5+10,2+11$ and $4+10.1$, found in this study, were not among them. Yasmeen et al. (2015) analyzed 242 lines of wheat, including landraces from the provinces of Punjab and Baluchistan, as well as the commercial varieties of Pakistan, and observed rare and uncommon variants in the Glu-B1 locus. Five subunits, reported in this study, including 
the three pairs in the Glu-D 1 , were not detected by the authors. Ribeiro et al. (2013) studied the Portuguese wheat Barbela and reported a new x-type HMW-GS encoded at the Glu-A1 locus that was named 1Ax1.1., while Ravel et al. (2014) discovered Glu-B1-1 protein 22 in Fruh-weizen (13310) wheat accession. We investigated nine SHW and reported 11 subunits (3 at the $G l u-D^{\mathrm{t}} 1$ locus) as compared to Rasheed et al. (2012) analyzing ninety-five Elite-1 synthetic hexaploid wheats (Triticum turgidum/Aegilops tauschii) with 22 glutenins (13 at the Glu- $D^{\mathrm{t}} 1$ locus). Five subunits $(1.1,14+15,22,2+11$ and $4+10.1$ ) reported here, were not present in the Elite- 1 subset. Two of them, the pairs $2+11$ and $4+10.1$, encoded at the Glu- $D^{\mathrm{t}} 1$ locus, are the HMW-GS published for the first time.

Trait variation in the SHW lines may contribute beneficial grain quality to modern wheat cultivars through introgression of novel allelic diversity.

\section{Acknowledgement}

We thank Dr. J. Valkoun for providing the samples of emmer wheats from ICARDASyria and the IPGR, supporting the Aegilops tauschii accessions.

\section{References}

Bahraei, S., Saidi, A., Alizadeh, D. 2004. High molecular weight glutenin subunits of current bread wheats grown in Iran. Euphytica 137:173-179.

Branland, G., Dardevet, M. 1985. Diversity of grain protein and bread wheat quality. II. Correlation between high molecular weight subunits of glutenin and flour quality characteristics. J. Cereal Sci. 3:345-354.

Feldman, M. 2001. Origin of cultivated wheat. In: Bonjean, A.P., Angus, W.J. (eds), The World Wheat Book: A History of Wheat Breeding. Lavoisier Tech \& Doc. Paris, France. pp. 3-56.

Giraldo, P., Rodriguez-Quijano, M., Simon, C., Vazquez, J.F., Carrillo, J.M. 2010. Allelic variation in HMW glutenins in Spanish wheat landraces and their relationship with bread quality. Span. J. Agric. Res. 8:10121023.

Goncharov, N.P., Bannikova, S.V., Kawahara, T. 2007. Wheat artificial amphiploids involving the Triticum timopheevii genome: their studies, preservation and reproduction. Gen. Res. Crop Evol. 54:1507-1516.

Goncharov, N.P., Golovina, K.A., Kondratenko, E.Y. 2009. Taxonomy and molecular phylogeny of natural and artificial wheat species. Breeding Sci. 59:492-498.

Lafiandra, D., D’Ovodio, R., Porceddu, E., Margiotta, B., Colaprico, G. 1993. New data supporting high molecular glutenin subunit 5 as the determinant of quality differences among the pairs $5+10$ and $2+12$. J. Cereal Sci. 18:197-205.

Li, J., Wan, H., Yang, W. 2014. Synthetic hexaploid wheat enhances variation and adaptive evolution of bread wheat in breeding processes. J. Syst. Ev. 52:735-742.

Ma, Y., Chen, G., Zhang, L., Liu, Y., Liu, D., Wang, J., Pu, Z., Zhang, L., Lan, X., Wei, Y., Liu, C., Zheng, Y. 2014. QTL mapping for important agronomic traits in synthetic hexaploid wheat derived from Aegilops tauschii ssp. tauschii. J. Integr. Agric. 13:1835-1844.

McIntyre, C.L., Rattey, A., Kilian, A., Dreccer, M.F., Shorter, R. 2014. Preferential retention of chromosome regions in derived synthetic wheat lines: a source of novel alleles for wheat improvement. Crop Past. Sci. 65:125-138.

Mestiri, I., Chagué, V., Tanguy, A., Huneau, C., Huteau, V., Belcram, H., Coriton, O., Chalhoub, B., Jahier, J. 2010. Newly synthesized wheat allohexaploids display progenitor-dependent meiotic stability and aneuploidy but structural genomic additivity. New Phytologist 186:86-101. 
Nei, M. 1973. Analysis of gene diversity in subdivided populations. Proc. Natl Acad. of Sci. USA 70:33213323.

Niwa, K., Aihara, H., Yamada, A., Motohashi, T. 2010. Chromosome number variations in newly synthesized hexaploid wheats spontaneously derived from self-fertilization of Triticum carthlicum Nevski/Aegilops tauschii Coss. $\mathrm{F}_{1}$ hybrids. Cereal Res. Commun. 38:449-458.

Payne, P.I. 1987. Genetics of wheat storage proteins and the effect of allelic variations on bread-making quality. Ann. Rev. Plant Physiol. 38:141-153.

Plamenov, D., Spetsov, P. 2011. Synthetic hexaploid lines are valuable resources for biotic stress resistance in wheat improvement. J. Plant Pathol. 93:251-262.

Rasheed, A., Safrad, T., Gul-Kazi, A., Mahmood, T., Akram, Z. 2012. Characterization of HMW-GS and evolution of their diversity in morphologically elite synthetic hexaploid wheats. Breeding Sci. 62:365-372.

Rasheed, A., Xia, X., Ogbonnaya, F., Mahmood, T., Zhang, Z., Mujeeb-Kazi, A., He, Z. 2014. Genome-wide association for grain morphology in synthetic hexaploid wheats using digital imaging analysis. BMC Plant Biol. 14:128-149.

Ravel, C., Fiquet, S., Boudet, J., Dardevet, M., Vincent, J., Merlino, M., Michard, R., Martre, P. 2014. Conserved cis-regulatory modules in promoters of genes encoding wheat high-molecular-weight glutenin subunits. Front. Plant Sci. Vol. 5, article 621, doi: 10.3389/fpls.2014.00621. http://www.ncbi.nlm.nih.gov/ pmc/articles/PMC4228979/

Ribeiro, M., Bancel, E., Faye, A., Dardevet, M., Ravel, C., Branlard, G., Igrejas, G. 2013. Proteogenomic characterization of novel x-type high molecular weight glutenin subunit 1Ax1.1. Int. J. Mol. Sci. 14:56505667.

Singh, N.K., Shepherd, K.W., Cornish, G.B. 1991. A simplified SDS-PAGE procedure for separating LMW subunits of glutenins. J. Cereal Sci. 14:203-208.

Tang, Y., Yang, W., Tian, J., Li, J., Chen, F. 2008. Effect of HMW-GS 6+8 and 1.5+10 from synthetic hexaploid wheat on wheat quality traits. Agric. Sci. China 7:1161-1171.

William, M.D.H., Peña, R.J., Mujeeb-Kazi, A. 1993. Variation of seed proteins and isozymes in the T. tauschii (Ae. squarrosa $2 \mathrm{n}=2 \mathrm{x}=14$, DD). Theor. Appl. Genet. 87:257-263.

Yasmeen, F., Khurshid, H., Ghafoor, A. 2015. Genetic divergence for high-molecular weight glutenin subunits $(H M W-G S)$ in indigenous landraces and commercial cultivars of bread wheat of Pakistan. Genet. Mol. Res. 14:4829-4839. 